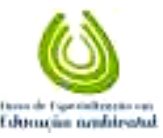

ACOSTA \& ROSITO, vol.(4), nº 4 , p. 903-914, 2011. Monografias Ambientais $\quad$ (e-ISSN: 2236-1308)

REMOA

\title{
PERCEPÇÃO AMBIENTAL DE ALUNOS DO CURSO PROFISSIONALIZANTE DE PANIFICAÇÃO - PROEJA FIC, CACEQUI (RS).
}

\section{ENVIRONMENTAL AWARENESS OF STUDENTS OF VOCATIONAL COURSE OF BAKERY - PROEJA FIC Cacequi (RS).}

\author{
LARA MARGARIDA DA SILVEIRA ACOSTA', JUMAIDA MARIA ROSITO² \\ 1 Acadêmica do Curso de Especialização em Educação Ambiental da Universidade Federal de Santa Maria (UFSM), \\ RS, Brasil. \\ acostabio@yahoo.com.br \\ Prof. Adjunto do Departamento de Biologia, Centro de Ciências Naturais e Exatas, UFSM, RS, Brasil.
}

\section{RESUMO}

Esse trabalho teve como objetivo avaliar o grau de ecoalfabetização de alunos do Curso Profissionalizante de Panificação, modalidade Educação para Jovens e adultos (EJA), de uma escola pública do município de Cacequi (RS, Brasil); com isso, espera-se contribuir para a melhoria da qualidade das aulas de Ciências Naturais do Curso e com a ampliação da consciência ambiental de seus alunos. $O$ instrumento utilizado foi a aplicação, em aula, de um questionário fechado abordando questões variadas da área ambiental, mas que privilegiava aqueles assuntos divulgados pelos meios mais facilmente acessados pela população, como televisão e jornais; da mesma forma, foi dado destaque aos temas de interesse nacional e regional. A análise das respostas evidenciou que, em sua maioria, os alunos desconhecem as questões ambientais abordadas pelo questionário, mesmo aquelas que estão presentes no seu dia a dia. Torna-se assim evidente, a necessidade de interferência por parte da escola no sentido de levar informação e de estimular uma atitude mais participativa de seus alunos, dando a eles a oportunidade de tornarem-se cidadãos ecoalfabetizados e comprometidos com seu mundo.

Palavras-chave: EJA; Ciências Naturais; Educação Ambiental

\section{ABSTRACT}

This study aimed to evaluate the degree of ecological knowledge of students at the Training Course on Bakery, modality Education for Youth and Adults (EJA), a public school in the municipality of Cacequi (RS, Brazil); with this, we hope to contribute to improving the quality of the teaching of Natural Sciences Course and an expansion of environmental awareness of their students. The instrument was applied in class of a closed questionnaire addressing a variety of environmental issues, but one which favored those matters disclosed by the most easily accessed by the population, such as television and newspapers in the same way, prominence was given to issues of national and regional interest. The analysis of responses showed that, in most cases, students are unaware of the environmental issues addressed by the questionnaire, even those that are present in their day to day. Thus becomes evident, the need for interference by the 


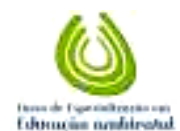

\section{ACOSTA \& ROSITO, vol.(4), nº, p. 903-914, 2011. Monografias Ambientais (e-ISSN: 2236-1308)}

REMOA

school in bringing information and encourage a more participatory attitude of his students, giving them the opportunity to become citizens committed to their world.

Keywords: EJA; Natural Sciences; Environmental awareness.

\section{INTRODUÇÃO}

A consolidação de novos modelos de desenvolvimento sustentável no país exige a construção de alternativas de utilização dos recursos naturais, orientada por uma racionalidade ambiental e uma ética da solidariedade que é construída através da educação ambiental. Entende-se por Educação Ambiental os processos por meio dos quais o indivíduo e a coletividade constroem valores sociais, conhecimentos, habilidades, atitudes e competências voltadas para a conservação do meio ambiente, bem de uso comum, essencial à sadia qualidade de vida (BRASIL, 1999). A educação ambiental é um processo permanente e objetiva mudanças sociais e culturais no conjunto da sociedade, tanto no que se refere à questão da sensibilização como também na tomada de decisões e ações frente aos problemas ambientais enfrentados (UNESCO, 1987). Ela traz consigo práticas e ações que ultrapassam as barreiras entre a educação formal e não-formal (Carvalho, 1988). Porém, face ao desenvolvimento do pensamento ambientalista ainda existe um enorme distanciamento entre o plano das intenções e a efetivação das ações necessárias e urgentes, dificultando a percepção dos indivíduos para o assunto (MELO, 2006; TILBURY; WALFORD, 1996).

A escolas e professores têm enfrentado muitos obstáculos para desenvolver a Educação Ambiental no país e principalmente em nível de município. A questão ambiental firma-se como um dos temas mais importantes do nosso tempo. Por esse viés, justifica-se a presença da Educação Ambiental em todos os níveis e modalidades de ensino, sejam eles de caráter formal ou informal.

Foi a partir da década de 30, que a educação de jovens e adultos (EJA) começou a delinear seu lugar na história da educação no país; nesse momento, se consolidava um sistema público de educação elementar do Brasil; nesse período, a sociedade brasileira passava por grandes transformações, associadas ao processo de industrialização e concentração populacional em centros urbanos. A partir da década de 40 , cresceram os esforços no sentido de extender o ensino aos jovens e adultos (RIBEIRO, 1997). A EJA é uma forma de ensino da rede pública no Brasil, e objetiva levar o ensino fundamental e o ensino médio de qualidade para as pessoas que não possuem idade escolar e tampouco tiveram oportunidades de estudar. Os alunos da EJA são geralmente trabalhadores/as, empregados/as ou não, que não tiveram acesso à cultura letrada. A auto-estima desses alunos, muitas vezes considerada baixa, pode ser facilmente superada pela determinação e pela conquista de mais uma vitória, nas tantas batalhas por eles já vencidas. A bagagem de experiências e informações que os alunos da EJA trazem para a sala de aula amplia mais ainda a visão do educador, ressignificando saberes através de atividades que dão sentido ao ato de ler e escrever. Pelo diálogo constante, o professor tem consciência dos problemas locais, das necessidades de cada bairro da cidade, da onipresença de gestores e do descaso de muitos professores. O educador é estimulado, a cada instante, a passar conhecimentos de uma nova visão ambiental aos alunos. Ele cumpre, em sala de aula, uma função social, na medida em que leva seus alunos a tornarem-se cidadãos 


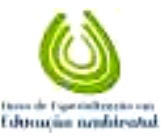

REMOA

\section{ACOSTA \& ROSITO, vol.(4), nº, p. 903-914, 2011. Monografias Ambientais (e-ISSN: 2236-1308)}

conscientes da realidade em que estão inseridos.

Na Escola Municipal Eulália Irion, no município de Cacequi (RS, Brasil), as aulas de Ciências Naturais para a EJA, são promovidas sempre com muito diálogo sobre os assuntos do dia a dia, em nível local, regional e mundial. Procuram-se metodologias diferenciadas a cada dia, estimulando sempre trabalhos individuais e em grupo. Na escola evita-se a abordagem tradicional, onde são oferecidos textos com questões seqüenciadas; é privilegiada a interação com textos reais, presentes no cotidiano dos alunos. Estas ações, normalmente, são concretizadas através de atividades que envolvem diretamente alunos, dentro e fora da escola. A reflexão dos problemas ambientais locais estabelece este tipo de ligação, gerando novas relações entre a escola e a comunidade, proporcionando a compreensão da realidade socioambiental que se apresenta em torno das mesmas.

Dentro deste contexto e buscando subsídios para o aprimoramento da abordagem das questões ambientais, esse trabalho teve como objetivo investigar o grau de ecoalfabetização dos alunos do Curso Profissionalizante de Panificação, modalidade Educação para Jovens e adultos (EJA), de uma escola pública do município de Cacequi (RS, Brasil).

\section{MATERIAIS E MÉTODOS}

Esse trabalho foi realizado na Escola Municipal Eulália Irion, no município de Cacequi, RS, Brasil. Para aferir o grau de ecoalfabetização de alunos da Educação de Jovens e Adultos (EJA) da escola avaliada, foi escolhida uma das turmas, num total de 22 alunos do curso profissionalizante de Panificação. Durante uma aula de Ciências, os alunos foram convidados a responder um questionário, que foi construído de forma a abranger diversos aspectos da vida no planeta. As questões foram elaboradas a partir de informações retiradas de meios de comunicação mais populares, como jornais e revistas e matérias veiculadas pela mídia televisiva.

\section{Do crescimento populacional}

FATO VERDADEIRO: Segundo o IBGE (Instituto Brasileiro de Geografia e Estatística), desde a década de 60 , a populacão brasileira cresce a taxas cada vez menores.

O fenômeno de redução da população (taxa de crescimento negativa) será observado no Rio Grande do Sul anos antes de atingir todo o país; o crescimento da populacional do Estado está em queda desde o início do século 21.

Na sua opinião, esta informação está correta ( ) incorreta（ )

Na sua opinião, a população brasileira atual está entre

$90-100$ milhões（） $100-200$ milhões（） 200-300 milhões（）. 
REMOA

\section{Monografias Ambientais $\quad$ (e-ISSN: 2236-1308)}

Da poluição

1.FATO VERDADEIRO: Pesquisadores da Universidade de Victoria (Canadá), afirmam que só um corte de $60 \%$ nas emissões de gases-estufa até 2050 evitará que, até o fim deste século, a Terra aqueça mais de $2 \stackrel{\circ}{ } \mathrm{C}$ além do normal - nível considerado perigoso por cientistas.

A 15a conferência das Nações Unidas sobre mudança climática, que ocorreu em 2009, em Copenhage, terminou sem um acordo definitivo para combater a mudança do clima no planeta. Não houve consenso nem mesmo em torno de proposta que defendia o aumento máximo de $2^{\circ} \mathrm{C}$ na temperatura global

Na sua opinião, esta informação está correta ( ) incorreta ( ).

2. FATO VERDADEIRO: São Paulo é a primeira capital brasileira com o nível mais acentuado de concentração de poeira fina no ar, relacionada à queima de combustível, à pavimentação e ao atrito do pneu no asfalto.

Na sua opinião, a segunda capital é

Curitiba ( ) Porto Alegre ( ) Rio de Janeiro ( )

Do desmatamento e extinção de espécies

1. FATO: 0 desmatamento acelerado que atingiu todos os ecossistemas de florestais no Brasil nas últimas décadas, seja para expansão da fronteira agrícola, seja para a exploração de madeira, é apontado, pela quase totalidade dos ambientalistas, como a principal causa do processo de extincão de

espécies.

Entre 2000 e 2005, o desmatamento da Amazônia já provocou a extinção de quase 30 espécies conhecidas de animais e plantas e colocou mais de 600 em risco.

Na sua opinião, esta informação está correta ( ) incorreta ( ).

Após três anos de investigações, a organização não governamental

Greenpeace concluiu um estudo que a indústria da pecuária nacional é a maior responsável pelo desmatamento da Amazônia

Na sua opinião, esta informação está correta ( ) incorreta ( ). 


\section{0 \\ ACOSTA \& ROSITO, vol.(4), nº 4, p. 903-914, 2011. Monografias Ambientais (e-ISSN: 2236-1308)}

REMOA

Felizmente, segundo relatórios da ONG ambientalista IUCN (The International Union Conservation of Nature), na última década o Brasil não aparece mais entre os cinco países com maior número de espécies em risco de extinção.

Na sua opinião, esta informação está correta ( ) incorreta ( ).

2. FATO: A Mata Atlântica já chegou a cobrir 39,7\% do Rio Grande do Sul. Em 1995 , sobravam menos de $3 \%$.

Segundo dados do início de 2009, da Secretaria Estadual do Meio Ambiente, a floresta já ocupa $7 \%$ da área original. Para isso, contribuíram a diminuição do desmatamento e ações de recuperação.

Na sua opinião, esta informação está correta ( ) incorreta ( ).

\section{Do lixo}

FATO: Estudos europeus apontam para dados preocupantes de concentração de princípios ativos de medicamentos na água. O tratamento e purificação da água elimina microorganismos, mas não prevê a retirada de compostos dissolvidos.

Os medicamentos com prazo de validade vencidos ou que não serão mais utilizados não devem ser descartados na pia ou vaso sanitário; se necessário, devem ser bem embalados e depositados no lixo comum

Na sua opinião, esta informação está correta ( ) incorreta ( ).

\section{RESULTADO E DISCUSSÃO}

Os alunos foram questionados sobre seu conhecimento sobre o crescimento populacional no RS. Apenas metade deles $(54,4 \%)$, tem noção da tendência de crescimento populacional no Estado(Figura 1). 
ACOSTA \& ROSITO, vol.(4), nº 4 , p. 903-914, 2011.

\section{Monografias Ambientais (e-ISSN: 2236-1308)}

\section{Crescimento populacional no RS.}

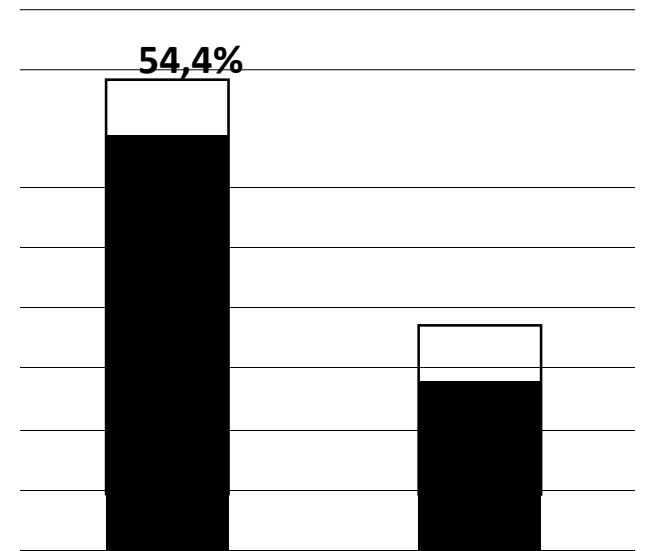

Figura 1 - Índices de acertos e erros (\%) na questão acerca da tendência de crescimento populacional no RS.

Da mesma forma, $27 \%$ dos alunos têm noção do tamanho populacional do Brasil, que está entre 100 e 200 milhões de habitantes (Figura 2).

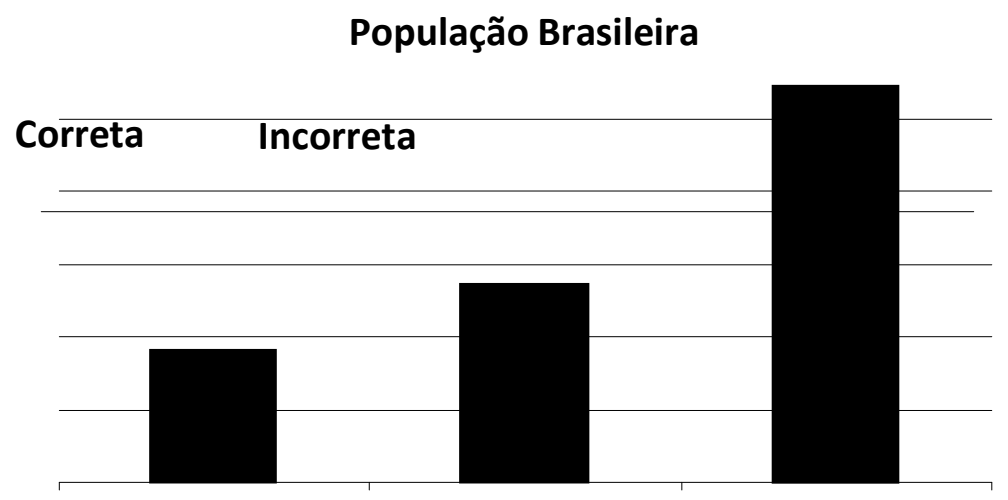

$18,2 \%$

$90-100$

$100-200$

200-300

Figura 21 - Índices de respostas (\%) para a estimativa do tamanho populacional brasileiro.

A terceira questão enfocava a poluição, e trazia em sua raiz a informação de que só um corte radical nas emissões de gases-estufa até 2050, evitaria o aquecimento global em índices perigosos para a vida. Apesar do assunto amplamente divulgado, verificou-se que $72 \%$ dos alunos desconhecem os desdobramentos da 15a conferência das Nações Unidas sobre mudança climática, em 2009, que foi um desastre amplamente divulgado pela mídia (Figura 3). 
(())
REMOA
ACOSTA \& ROSITO, vol.(4), ${ }^{\circ} 4$, p. 903-914, 2011.

Monografias Ambientais (e-ISSN: 2236-1308)

\section{Mudanças Climáticas}

$80 \%$

\section{$72,7 \%$}

$70 \%$

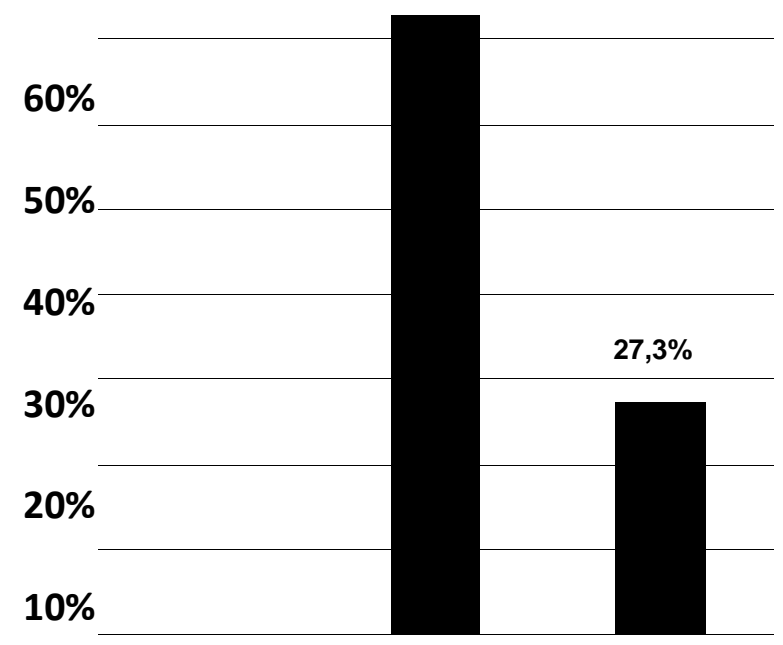

Incorreta Correta

Figura 3 - Índices de acertos e erros (\%) na questão acerca da $15^{a}$ Conferência das Nações Unidas sobre mudança climática.

Ainda sobre a poluição, quando perguntados sobre a segunda capital mais poluída entre Curitiba, Porto Alegre e Rio de Janeiro, 22,7\% afirmaram que a capital de nosso estado é a segunda capital com maior concentração de poeira fina no ar; a maioria $68,2 \%$ acredita que é o Rio de Janeiro, como se esse problema estivesse bem longe, nos lugares mais em evidência (São Paulo e Rio). São Paulo é a primeira capital brasileira com o nível mais acentuado de concentração de poeira fina no ar, relacionada à queima de combustível, à pavimentação e ao atrito do pneu no asfalto. Esse resultado pode ser observado na figura 4. 
ACOSTA \& ROSITO, vol.(4), $n^{\circ} 4$, p. 903-914, 2011.

REMOA

\section{Monografias Ambientais (e-ISSN: 2236-1308)}

\section{Poluição - Nível de poeira.}

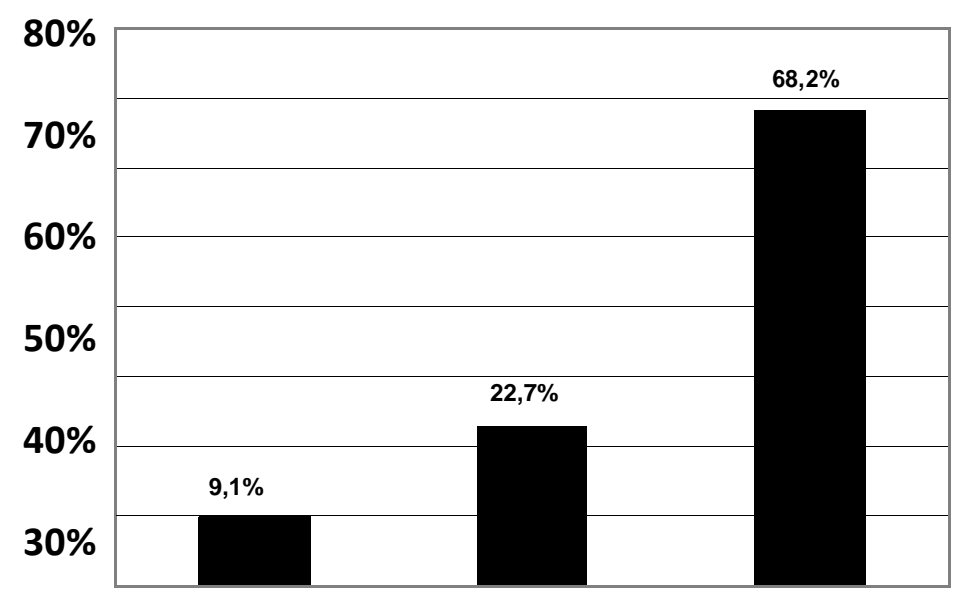

$20 \%$

$10 \%$

$0 \%$

\section{Curitiba Porto Alegre Rio de Janeiro}

Figura 4 - Índices de respostas (\%) com relação à opinião sobre a segunda capital brasileira com maior concentração de poeira fina no ar.

Ao serem questionados sobre desmatamento e extinção de espécies felizmente, $100 \%$ dos alunos têm noção dos dados reais, concordando que o desmatamento acelerado que atingiu todos os ecossistemas de florestas no Brasil nas últimas décadas, seja para a expansão da fronteira agrícola, seja para a exploração de madeira, é apontado, pela quase totalidade dos ambientalistas, como a principal causa do processo de extinção de espécies.

Contudo, na outra questão sobre tema similar, mais de $77 \%$ não sabe que a pecuária é a grande responsável pelo desmatamento da Amazônia (Figura 5).

Desmatamento e extinção.

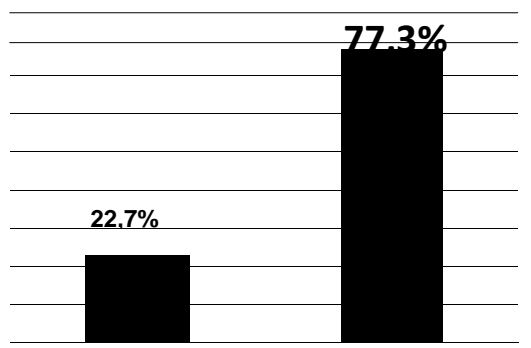


Figura 5 - Índices de acertos e erros (\%) na questão acerca da pecuária como grande responsável pelo desmatamento na Amazônia.

Ainda sobre desmatamento e extinção de espécies, quase a metade dos entrevistados, 40,9\%, acredita que o Brasil não está mais entre os países com maior número de espécies em extinção, segundo a ONG ambientalista IUCN (The International Union Conservation of Nature) (Figura 6).

IUCN

$60 \%$

\section{$54,5 \%$}

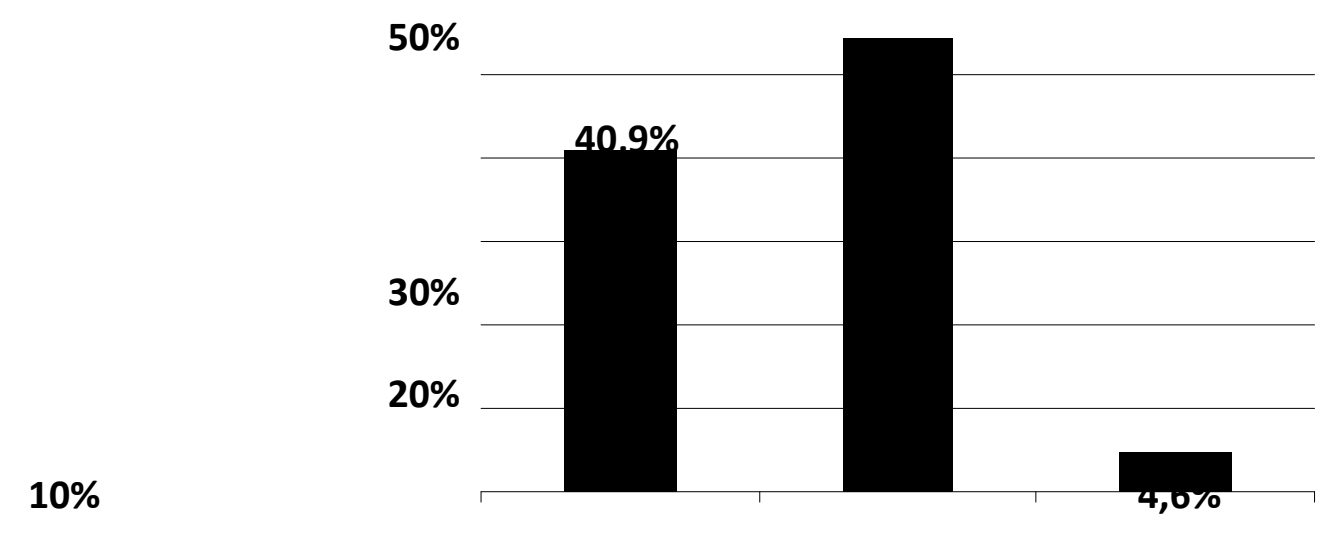

$0 \%$
Correta
Incorreta
n.d.a.

Figura 62 - Índices de aceros e erros (\%) acerca da questão sobre extinção de espécies no Brasil.

Surpreendentemente, mais de $72 \%$ aceita como real a notícia de que a Mata Atlântica está sendo recuperada, comopode ser observado pela análise dos dados do início de 2009, da Secretaria Estadual do Meio Ambiente (Figura 7). 
ACOSTA \& ROSITO, vol.(4), nº 4, p. 903-914, 2011.

REMOA

\section{Monografias Ambientais (e-ISSN: 2236-1308)}

\section{Mata Atlântica}

$80 \%$

$70 \%$

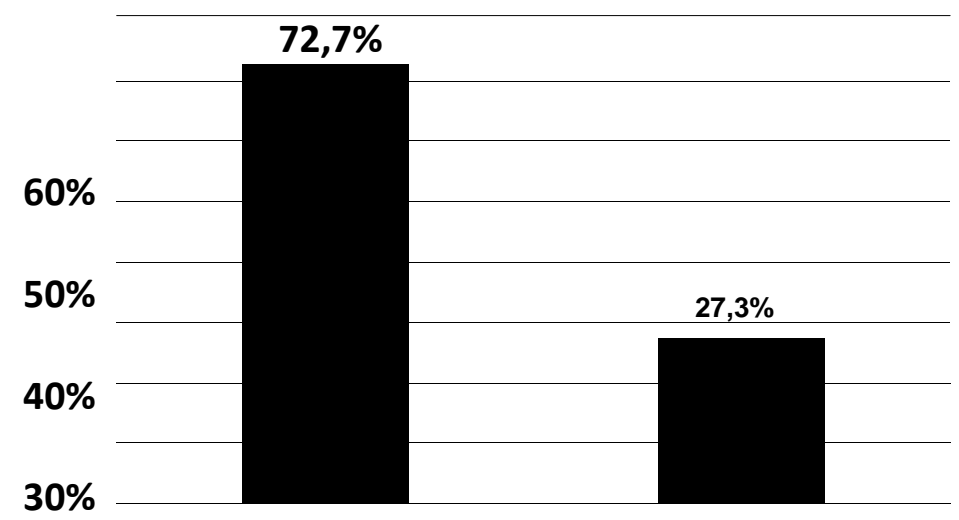

$20 \%$

$10 \%$

$0 \%$
Correta
Incorreta

Figura 7 - Índices de acertos e erros (\%) na questão acerca da recuperação da Mata Atlântica no RS.

Mas, de todos os dados obtidos, a informação mais grave é que metade da turma acha que podemos descartar medicamentos no lixo comum, desde que os mesmos sejam devidamente embalados (Figura 8). 


\section{Lixo}

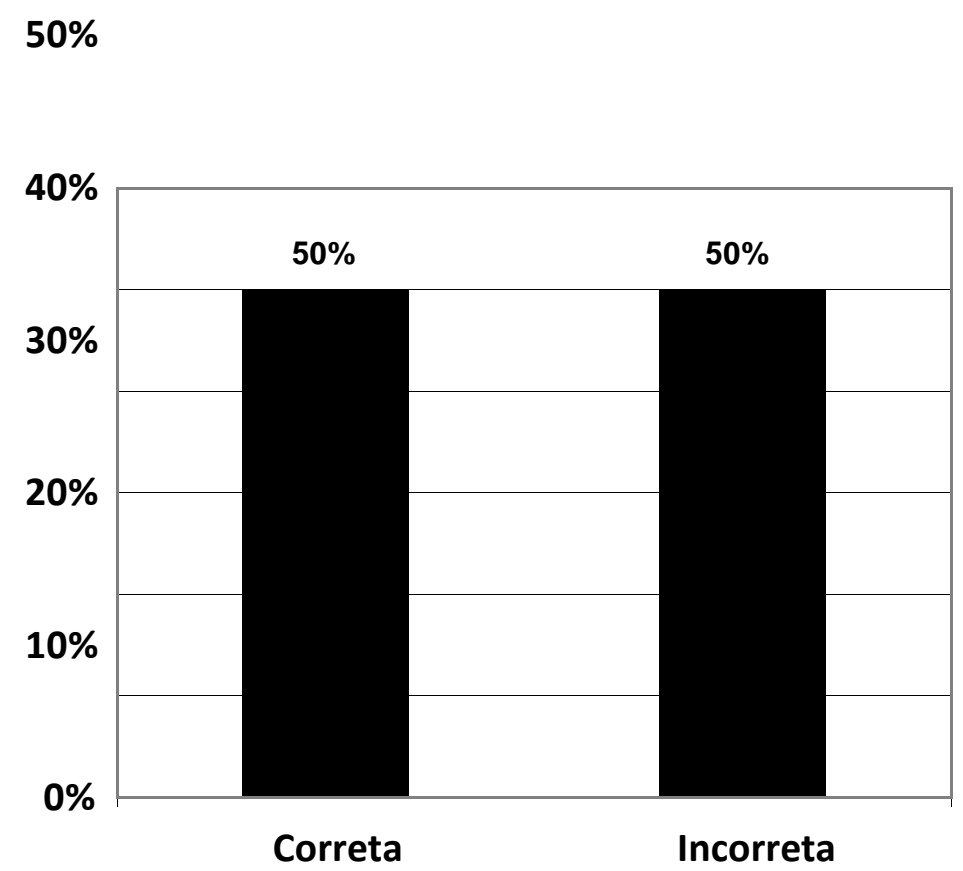

Figura 8 - Índices de acertos e erros (\%) na questão acerca do descarte de medicamentos no lixo comum.

Com esse trabalho, foi possível constatar que a dificuldade mais evidente parece ser a falta de informação. Para que mudanças bem-vindas na estratégia de ensino sejam efetivadas, é necessário que os educadores tenham, em primeiro lugar, a exata noção do grau de conhecimento de seus alunos sobre as questões básicas da problemática ambiental. Nesse aspecto, o uso de instrumentos, como aplicação de questionários ou debates diretos, podem alavancar mudanças de postura de ambos os lados. Foi muito significativo encarar, de forma tão clara, a simplória ignorância dos preceitos básicos de convivência desses alunos, sujeitos do estudo, com seu meio ambiente. Com certeza, através das questões levantadas pelo questionário e dos debates por ele gerados, eles também obtiveram ciência de que há necessidade de ampliar sua visão de mundo, tomando para si a parte que lhes cabe na responsabilidade de preservar e respeitar o planeta.

Para colaborar com outras iniciativas como a desse trabalho, parece pertinente expor algumas idéias que podem lapidar essa prática. Recomenda-se, especialmente, a cuidadosa adequação da linguagem à realidade dos alunos avaliados. É possível que a falta de compreensão de questões propostas tenha comprometido algumas das respostas, embora todas as dúvidas levantadas tenham sido prontamente esclarecidas durante o processo de avaliação. Mas, em sua concepção original, o questionário deve ser claro, auto-explicativo e adequado, de forma a não haver interferência do professor durante sua aplicação. Só assim, podemos avaliar, com precisão, o comprometimento dos alunos nessas questões.

Pelas experiências vividas no ensino de Ciências Naturais para a EJA, especialmente com conteúdos que envolvem educação ambiental, cada vez mais torna-se evidente a necessidade de proporcionar aos educadores condições para que possam conduzir práticas pedagógicas 


\section{ACOSTA \& ROSITO, vol.(4), ${ }^{\circ} 4$, p. 903-914, 2011. Monografias Ambientais

REMOA

adequadas; essas, devem incentivar o debate, a pesquisa de mundo, a construção do conhecimento e a reflexão sobre as questões ambientais, visando o desenvolvimento da consciência e da cidadania.

Para tanto é necessário investir em uma maior capacitação desses profissionais e a construção conjunta de mecanismos para superar entraves.

Deve-se salientar, ainda, que, apesar dos currículos de ensino proporcionarem a oportunidade de aquisição dos conhecimentos necessários à compreensão da problemática ambiental, o sistema educacional parece não conseguir alcançar com êxito esse objetivo, impedindo, ao lado de outras dificuldades, que a sociedade brasileira se engaje na construção de um novo estilo de desenvolvimento.

\section{CONCLUSÃO}

Uma vez que para esse trabalho seria considerado ecoalfabetizado o cidadão com consciência dos fatos ligado ao seu ambiente, quer numa escala restrita ou planetária, pode ser definido como pouco satisfatório o grau de ecoalfabetização dos alunos avaliados.

\section{REFERÊNCIAS BIBLIOGRÁFICAS}

BRASIL. Secretaria de Educação Fundamental. Educação para jovens e adultos: Ensino Fundamental primeiro segmento. São Paulo: Ação Educativa. Brasília: MEC, 1999.

CARVALHO, J.A.M. de. O tamanho da população brasileira e sua distribuição etária: uma visão prospectiva, São Paulo: ABEP, Anais $V$ Encontro Nacional de Estudos Populacionais, 1988. Disponível em: http://www.abmp.org.br/textos/361.htm Acesso em: 25 jun 2010.

MELO, Aline Fernandes; Refletindo a Educação Ambiental: Percepções e práticas dos Professores de Geografia em escolas públicas do município de Viçosa - MG, 2006.

RIBEIRO, Vera Maria Masagão. Educação de jovens e adultos: proposta curricular para o 1o segmento do ensino fundamental. São Paulo: Ação Educativa; Brasília: MEC, 1997.

TILBURY, D.; WALFORD, R. Grounded theoriy: defying the dominant paradigm in environmental education research. In: Understanding geographical and environmental education. Oxford: OUP, 1996.

UNESCO. Congresso Internacional UNESCO/PNUMA sobre la educacion y la Formacion Ambientales, Moscou, in: Educação Ambiental, Situação Espanhola e Estratégia Internacional. DGMA-MOPU, Madrid, 1987. 